\title{
An Improved Method of Optimizing the Extraction of Polyphenol Oxidase from Potato (Solanum tuberosum L.) Peel
}

\author{
Suprabhat MUKHERJEE ${ }^{* *}$, Bidyut BANDYOPADHAYAY², Bikram BASAK², \\ Nilrudra MANDAL ', Apurba DEY'3 Biswanath MONDAL ${ }^{1}$ \\ ${ }^{1}$ CSIR-Central Mechanical Engineering Research Institute, Centre for Advanced Materials Processing, \\ Durgapur-713209, India; suprabhat.biochem@hotmail.com (*corresponding author) \\ ${ }^{2}$ Oriental Institute of Science and Technology, Department of Biotechnology, Burdwan, India \\ ${ }^{3}$ National Institute of Technology, Department of Biotechnology, Durgapur, Mahatma Gandhi Avenue, Durgapur-713209, India
}

\begin{abstract}
The present study has an objective to optimize the extraction of Polyphenol Oxidase (PPO) from potato (Solanum tuberosum L.) peel. Response surface methodology (RSM) was used to design experiments and study the effect of six influential extraction parameters: extraction buffer concentration $(100-500 \mathrm{mM})$, $\mathrm{pH}$ of extraction buffer (4.5-8.5), time (1-12 hours), temperature (4- $\left.40^{\circ} \mathrm{C}\right)$, concentration of PMSF (1-5 mM) and volume of extraction buffer (200-1000 ml) on the extraction of PPO. The dependent variable was considered as response function which was specific activity (SA) of extracted PPO. ANOVA was performed to obtain the regression equation that could predict the responses within given range. From RSM generated model, the optimum conditions for the maximum extraction of PPO were phosphate buffer concentration of $100 \mathrm{~mm}$, buffer $\mathrm{pH}$ of 4.5 , extraction time of 1 hour, $40^{\circ} \mathrm{C}$ temperature, PMSF concentration of $5 \mathrm{mM}$ and buffer volume of $200 \mathrm{ml}$. Finally, this study illustrates a cost effective and less time consuming method to maximize the extraction of PPO from a vegetable waste.
\end{abstract}

Keywords: ANOVA, PPO regression equation, RSM, specific activity

List of abbreviation: ANOVA: Analysis of varience; BC: Buffer concentration; C.V.: Coefficient of variation; d.f.: Degrees of freedom; EA: Enzyme Activity; ET: Extraction time; ETM: Extraction temperature; F: Fisher variance ratio; p: Probability; PB: pH of extraction buffer; PC: PMSF concentration; PPO:Polyphenol oxidase; RSM: Response Surface Methodology; PMSF: Phenyl Methyl Sulfonyl Fluoride; R:Coefficient of variation; $\mathrm{R}^{2}$ : Coefficient of determination; SA: Specific Activity; VB: Volume of extraction buffer

\section{Introduction}

PPO is a copper-containing enzyme that catalyses both molecular oxygen-dependent hydroxylation of monophenols to their corresponding o-diphenols and oxidation of o-diphenols such as L-DOPA to their cognate o-quinones (Ni Eidhin et al., 2010; Palma-Orozco et al., 2011). Important properties of PPO viz. wider substrate specificity, ability of catalyzing reaction in wider range of $\mathrm{pH}$ and temperature (Seo et al., 2003), protease activity (GomezLopez, 2002) etc have been utilized for various purposes. The ability of oxidizing large group of phenolic compounds has been utilized in removal of phenolic contaminants from waste water, effluents and contaminated soil (Klibanov et al., 1980; López-Molina et al., 2003; Torres et al., 2003). The same property of PPO has also been utilized for removal of reactive textile dyes. Researchers have reported the use of both soluble and immobilized PPO in the biotransformation of phenolic contaminants but later provide better performance in terms of reusability and catalysis (Amjad et al., 2009; Duran et al., 2002; Niladevi and Prema, 2008). Immobilization of PPO onto porous and conducting surface has led to the development of biosensor for monitoring of aqueous phenolic components. Construction of biosensor using immobilized PPO on Carbon Nanotube (Mohammadi et al., 2009) and calcium carbonate nanoparticles (Shan et al., 2007) are the better examples of this fact. Since the enzymatic browning by PPO causes decrease of nutritional quality and affects the appearance of food, inactivation of PPO is desirable for preservation of foods (Langdon, 1987; Lee et al., 2007).

All these mentioned purposes require PPO either in crude or purified form. Therefore the need, demand and market value of PPO in its different fields of application is quite high. However, high production cost has limited the feasibility of its uses in industries. The cost of the sources of PPO is also a matter of concern. Keeping in view of the usefulness and cost effectiveness of PPO for various industrial purposes, it is very important to develop some analytical methods for the extraction of this enzyme in such a way that will be of high yield and cost effective. Usually, the method for determining optimal conditions in extraction processes is varying one parameter while keeping others at a constant level. This is a time consuming and cost 
ineffective method that does not include interaction effects among variables (Ranjan et al., 2009). Optimization employing central composite design (CCD) and response surface methodology (RSM) can overcome such drawbacks (Bas and Boyaci, 2007; Vohra and Satyanarayana, 2002). Researchers have reported the utility of CCD in optimization of experimental determinants (Ebrahimpour et al., 2008; Hameed et al., 2009) and RSM for process development as it provides all the information regarding the combinatorial effects of variables, regression modeling and optimization of the variables to maximize the desired product (Chen et al., 2002; Gaur et al., 2008; Manohar and Divakar, 2004; Sztajer et al., 1988).

Although considerable research works have been carried out on extraction, purification and characterization of PPO from various fruits and vegetables (Aydemir, 2010; Marri et al., 2003; Sener and Ümit Ünal, 2011; Yang et al., 2001). There was no evidence on the improvement of extraction of PPO from potato peel through statistical optimization. In this paper, RSM was conducted to study the effects of different influential extraction parameters to maximize the yield of PPO from potato peels. The optimum extraction conditions (environmental, process and solution parameters) were predicted and validated using statistical methodologies.

\section{Materials and methods}

\section{Plant materials}

Potato (Solanum tuberosum) peels were collected from the hotels near National Institute of Technology, Durgapur. These peels were washed several times with double distilled water and used for study. The reasons behind the selection of potato peels as experimental material were firstly, researchers have reported the presence of PPO in potato (Do-Yoon and Woo-Yean, 1996; Thygesen et al., 1995). Secondly, potato tuber is mainly used as the source of dietary carbohydrate whereas peels are mainly considered as waste and easily available. Therefore it is an economic source of PPO.

\section{Chemicals}

Di-sodium hydrogen phosphate $\left(\mathrm{Na}_{2} \mathrm{HPO}_{4}\right)$, Sodium di-hydrogen phosphate $\left(\mathrm{NaH}_{2} \mathrm{PO}_{4}\right)$, Sodium Hydroxide $(\mathrm{NaOH})$ and Catechol (Pyrocatechol) were purchased from Merck (Germany). Triton X-114 (Sigma-Aldrich, USA) and PMSF (Sisco research laboratory, India) were used in this study. All the chemicals used were of analytical grade commercially available in India.

\section{Development of suitable design matrix}

RSM was employed to find the optimum experimental condition with definite values of key experimental determinants for the maximum yield of PPO in the potato peel extract. The experimental design and statistical analysis was performed using design expert software. All the ex- periments were designed using central composite design (CCD) with a quadratic model in order to study the combined and individual effects of six influential experimental parameters on the extraction of PPO. These variables were $\mathrm{A}$ : concentration of the extraction buffer $(\mathrm{BC}), \mathrm{B}$ : $\mathrm{pH}$ of extraction Buffer (PB), C: extraction time (ET), D: extraction temperature (ETM), E: PMSF concentration in extraction buffer (PC) and F: volume of extraction buffer (VB). Each parameter had two levels which were-1 and +1 , shown in Tab. 1. A total of 74 sets of experiments were performed to determine significant factors for the extraction of PPO.

Specific activity (SA) of extracted PPO was considered as the only dependent variable or response function. As the objective of this study was to optimize the yield of PPO in the extract, the response, SA has been considered as key factor because optimization of SA will ensure maximum activity of PPO per mg of protein in the extract. Relationships between six parameters (BC, PB, ET, ETM, PC and $\mathrm{VB}$ ) and process responses (SA) for the extraction of $\mathrm{PPO}$ were analyzed using RSM. All the experimental conditions and value of the corresponding response studied are depicted in Tab. 2.

\section{Extraction of PPO}

One hundred g of potato peel was blended with phosphate buffer of different concentration and $\mathrm{pH}$ under different experimental conditions based on the combinations programmed by RSM (as per Tab. 2). 1\% Triton X-114 was also added to the extraction medium. The extraction was performed under continuously stirring using magnetic stirrer. After extraction each mixture was centrifuged at $18,000 \mathrm{rpm}$ for 20 minutes using a compufuge (Remi, India) and the supernatant was filtered through Whatman no. 4 filter paper. The filtrate was taken as crude enzyme extract and it was stored at $-20^{\circ} \mathrm{C}$.

\section{Assay of PPO}

PPO activity was assayed using the procedure of Oktay et al. (1995) with some modification. Briefly, $0.1 \mathrm{ml}$ en-

Tab. 1. Independent variables and their coded levels used in RSM studies

\begin{tabular}{cccc}
\hline & & \multicolumn{3}{c}{ Level } \\
\hline Factors & Units & $\begin{array}{c}\text { Low } \\
(-1)\end{array}$ & $\begin{array}{c}\text { High } \\
(1)\end{array}$ \\
\hline $\begin{array}{c}\text { A: Buffer Concentration of } \\
\text { Extraction Buffer (BC) }\end{array}$ & $\mathrm{mM}$ & 100 & 500 \\
B: Buffer Concentration of \\
Extraction Buffer (BC) & & 4.5 & 8.5 \\
\hline C: Extraction Time (ET) & Hours & 1 & 12 \\
\hline D: Extraction Temperature (ETM) & ${ }^{\circ} \mathrm{C}$ & 4 & 40 \\
\hline E: PMSF Concentration (PC) & $\mathrm{mM}$ & 1 & 5 \\
\hline F: Volume of Extraction Buffer (VB) & $\mathrm{ml}$ & 200 & 1000 \\
\hline
\end{tabular}


100

Tab. 2. CCD design for six variables showing observed values of SA of PPO

\begin{tabular}{|c|c|c|c|c|c|c|c|}
\hline Run & $\mathrm{A}: \mathrm{BC}(\mathrm{mM})$ & B: PB & C: ET (Hour) & D: ETM $\left({ }^{\circ} \mathrm{C}\right)$ & E: PC (mM) & $\mathrm{F}: \mathrm{VB}(\mathrm{ml})$ & $\begin{array}{c}\text { Response: } \\
\text { SA Unit/mg protein }\end{array}$ \\
\hline 1 & 300 & 6.5 & 6.5 & 22 & 3 & 600 & 3235 \\
\hline 2 & 300 & 6.5 & 6.5 & 22 & 3 & 600 & 3235 \\
\hline 3 & 500 & 4.5 & 12 & 4 & 5 & 200 & 3105 \\
\hline 4 & 500 & 4.5 & 12 & 40 & 1 & 1000 & 3112 \\
\hline 5 & 100 & 4.5 & 1 & 4 & 5 & 200 & 3383 \\
\hline 6 & 100 & 4.5 & 12 & 4 & 1 & 200 & 3309 \\
\hline 7 & 500 & 8.5 & 12 & 4 & 5 & 1000 & 3007 \\
\hline 8 & 300 & 6.5 & 6.5 & 22 & 3 & 600 & 3235 \\
\hline 9 & 500 & 4.5 & 1 & 40 & 5 & 200 & 3107 \\
\hline 10 & 100 & 8.5 & 12 & 40 & 1 & 1000 & 3381 \\
\hline 11 & 500 & 8.5 & 1 & 40 & 1 & 1000 & 3017 \\
\hline 12 & 100 & 8.5 & 12 & 40 & 5 & 200 & 3511 \\
\hline 13 & 500 & 8.5 & 1 & 40 & 1 & 200 & 3047 \\
\hline 14 & 500 & 4.5 & 12 & 40 & 5 & 200 & 3171 \\
\hline 15 & 500 & 8.5 & 12 & 4 & 5 & 200 & 3103 \\
\hline 16 & 500 & 4.5 & 1 & 4 & 1 & 1000 & 3043 \\
\hline 17 & 500 & 4.5 & 12 & 4 & 1 & 200 & 3103 \\
\hline 18 & 500 & 8.5 & 1 & 4 & 5 & 200 & 3077 \\
\hline 19 & 300 & 6.5 & 6.5 & 22 & 3 & 600 & 3235 \\
\hline 20 & 100 & 8.5 & 1 & 4 & 5 & 200 & 3305 \\
\hline 21 & 500 & 4.5 & 12 & 40 & 5 & 1000 & 3157 \\
\hline 22 & 500 & 4.5 & 12 & 40 & 1 & 200 & 3142 \\
\hline 23 & 500 & 8.5 & 12 & 4 & 1 & 200 & 3077 \\
\hline 24 & 100 & 8.5 & 12 & 4 & 1 & 200 & 3304 \\
\hline 25 & 500 & 8.5 & 12 & 40 & 1 & 200 & 3103 \\
\hline 26 & 100 & 8.5 & 1 & 40 & 5 & 1000 & 3357 \\
\hline 27 & 500 & 4.5 & 12 & 4 & 1 & 1000 & 3077 \\
\hline 28 & 100 & 8.5 & 1 & 40 & 1 & 200 & 3307 \\
\hline 29 & 100 & 8.5 & 1 & 40 & 5 & 200 & 3441 \\
\hline 30 & 100 & 4.5 & 12 & 4 & 5 & 200 & 3422 \\
\hline 31 & 300 & 6.5 & 6.5 & 22 & 3 & 600 & 3235 \\
\hline 32 & 500 & 8.5 & 1 & 4 & 5 & 1000 & 3043 \\
\hline 33 & 100 & 8.5 & 12 & 4 & 5 & 200 & 3357 \\
\hline 34 & 100 & 4.5 & 1 & 40 & 5 & 200 & 3493 \\
\hline 35 & 100 & 4.5 & 1 & 40 & 5 & 1000 & 3422 \\
\hline 36 & 500 & 4.5 & 1 & 4 & 1 & 200 & 3077 \\
\hline 37 & 100 & 8.5 & 1 & 4 & 1 & 200 & 3269 \\
\hline 38 & 500 & 4.5 & 1 & 4 & 5 & 200 & 3103 \\
\hline 39 & 500 & 8.5 & 1 & 4 & 1 & 1000 & 3000 \\
\hline 40 & 300 & 6.5 & 6.5 & 22 & 3 & 600 & 3235 \\
\hline 41 & 100 & 4.5 & 12 & 40 & 1 & 1000 & 3441 \\
\hline 42 & 100 & 8.5 & 1 & 4 & 1 & 1000 & 3263 \\
\hline 43 & 100 & 4.5 & 1 & 40 & 1 & 1000 & 3333 \\
\hline 44 & 300 & 6.5 & 6.5 & 22 & 3 & 600 & 3235 \\
\hline 45 & 100 & 4.5 & 1 & 4 & 5 & 1000 & 3306 \\
\hline 46 & 500 & 8.5 & 12 & 4 & 1 & 1000 & 3043 \\
\hline 47 & 500 & 4.5 & 1 & 40 & 1 & 200 & 3103 \\
\hline 48 & 100 & 4.5 & 12 & 40 & 1 & 200 & 3478 \\
\hline 49 & 500 & 8.5 & 12 & 40 & 5 & 1000 & 3142 \\
\hline 50 & 500 & 8.5 & 12 & 40 & 1 & 1000 & 3103 \\
\hline 51 & 500 & 4.5 & 12 & 4 & 5 & 1000 & 3103 \\
\hline
\end{tabular}


Tab. 2. CCD design for six variables showing observed values of SA of PPO (cont.)

\begin{tabular}{|c|c|c|c|c|c|c|c|}
\hline Run & $\mathrm{A}: \mathrm{BC}(\mathrm{mM})$ & $\mathrm{B}: \mathrm{PB}$ & C: ET (Hour) & D: $\operatorname{ETM}\left({ }^{\circ} \mathrm{C}\right)$ & $\mathrm{E}: \mathrm{PC}(\mathrm{mM})$ & $\mathrm{F}: \mathrm{VB}(\mathrm{ml})$ & $\begin{array}{c}\text { Response: } \\
\text { SA Unit/mg protein }\end{array}$ \\
\hline 52 & 100 & 8.5 & 12 & 4 & 5 & 1000 & 3307 \\
\hline 53 & 100 & 8.5 & 1 & 40 & 1 & 1000 & 3305 \\
\hline 54 & 500 & 4.5 & 1 & 4 & 5 & 1000 & 3077 \\
\hline 55 & 300 & 6.5 & 6.5 & 22 & 3 & 600 & 3235 \\
\hline 56 & 500 & 4.5 & 1 & 40 & 5 & 1000 & 3125 \\
\hline 57 & 500 & 8.5 & 1 & 40 & 5 & 200 & 3142 \\
\hline 58 & 100 & 8.5 & 12 & 40 & 5 & 1000 & 3461 \\
\hline 59 & 500 & 4.5 & 1 & 40 & 1 & 1000 & 3103 \\
\hline 60 & 500 & 8.5 & 1 & 40 & 5 & 1000 & 3103 \\
\hline 61 & 500 & 8.5 & 12 & 40 & 5 & 200 & 3157 \\
\hline 62 & 100 & 4.5 & 12 & 40 & 5 & 1000 & 3550 \\
\hline 63 & 100 & 4.5 & 12 & 40 & 5 & 200 & 3616 \\
\hline 64 & 300 & 6.5 & 6.5 & 22 & 3 & 600 & 3235 \\
\hline 65 & 300 & 6.5 & 6.5 & 22 & 3 & 600 & 3235 \\
\hline 66 & 500 & 8.5 & 1 & 4 & 1 & 200 & 3043 \\
\hline 67 & 100 & 4.5 & 12 & 4 & 1 & 1000 & 3305 \\
\hline 68 & 100 & 4.5 & 1 & 4 & 1 & 1000 & 3271 \\
\hline 69 & 100 & 4.5 & 1 & 40 & 1 & 200 & 3381 \\
\hline 70 & 100 & 4.5 & 12 & 4 & 5 & 1000 & 3381 \\
\hline 71 & 100 & 8.5 & 12 & 4 & 1 & 1000 & 3273 \\
\hline 72 & 100 & 8.5 & 1 & 4 & 5 & 1000 & 3273 \\
\hline 73 & 100 & 4.5 & 1 & 4 & 1 & 200 & 3304 \\
\hline 74 & 100 & 8.5 & 12 & 40 & 1 & 200 & 3401 \\
\hline
\end{tabular}

zyme extract was added to $2.9 \mathrm{ml}$ of Catechol $(100 \mathrm{mM})$ in $0.1 \mathrm{M}$ phosphate buffer ( $\mathrm{pH}-6.5)$ solution and change in absorbance at $420 \mathrm{~nm}$ was measured using a dual beam UV-Visible spectrophotometer (UV 3600, Shimadzu, Japan) against reference $(3.0 \mathrm{ml}$ catechol). Change in absorbance was recorded every 1 second for 3 minutes. One unit of PPO activity was defined as the change in absorbance of 0.001 per minute per milliliter of enzyme. Finally, enzyme activity was expressed in units $/ \mathrm{ml}$. Activity measurements were carried out in triplicate.

\section{Measurement of specific activity of PPO}

Protein quantity was estimated from the supernatant of each extract by the method of Lowry et al. (1951) and protein quantity was expressed in $\mathrm{mg} / \mathrm{ml}$ using bovine serum albumin as standard. Specific activity (SA) of PPO was expressed in Units/mg of protein.

\section{Mathematical modeling}

Analysis of variance (ANOVA) was performed for the independent and dependent values to obtain regression equations that could predict the responses within a given range. The generalized second order regression equation used in the response surface study was as follows:

$$
Y=\beta_{0}+\sum_{i=1}^{6} \beta_{i} X_{i}+\sum_{i, j=1}^{6} \beta_{i j} X_{i} X_{j}+\sum_{i=1}^{6} \beta_{i i} X_{i}^{2}
$$

Where $Y$ is the predicted response, $\beta_{0}, \beta_{i}, \beta_{i i}$, and $\beta_{i i}$ are the regression coefficients for intercept, linear, quadratic and interaction terms, respectively, and $\mathrm{X}_{i}$, and $\mathrm{X}_{\text {a }}$ are the independent variables. For coded independent variables $(\mathrm{A}, \mathrm{B}, \mathrm{C}, \mathrm{D}, \mathrm{E}$ and $\mathrm{F})$, the selected polynomial equation could be expressed as:

$Y=\beta_{0}+\beta_{1} A+\beta_{2} B+\beta_{3} C+\beta_{4} D+\beta_{5} E+\beta_{6} F+\beta_{12} A B$ $+\beta_{13} \mathrm{AC}+\beta_{14} \mathrm{AD}+\beta_{15} \mathrm{AE}+\beta_{16} \mathrm{AF}+\beta_{23} \mathrm{BC}+\beta_{34} \mathrm{CD}+$ $\beta_{45} D E+\beta_{56} E F+\beta_{11} A^{2}$

The design expert software was used to generate response surfaces and three dimensional (3D) plots. The adequacy and significance of the regression model was tested using ANOVA method. Test for significance on individual model coefficients and test for lack-of-fit was also estimated.

\section{Determination of optimum extraction and validation of} the final model

Optimum condition for the possible maximum extraction of PPO from potato peel depends on all the six parameters were obtained using the predictive equation of RSM. The software design expert was applied to search the optimum desirability of the response which is maximum SA of PPO. The verification of the validity and adequacy of the predictive extraction model with respect to all the six variables within the design space was done by performing a random set of 6 experimental combinations to study specific activity. Three verification run experiments were previously and remaining three experiments were those which have not been used but are within the range of the 
102

levels defined previously. The experimental and predictive values of SA were compared to validate the model.

\section{Results and discussion}

\section{ANOVA analysis}

As summarized in Tab. 3, the ANOVA analysis of response 1: SA, the model F-value of 328.96 implies the model is significant. There is only a $0.01 \%$ chance that a "Model F-Value" could be large which may occur due to noise. Values of "Prob > F" less than 0.0500 indicate model terms are significant. In this case A, B, C, D, E, F, AB, $\mathrm{AC}, \mathrm{AD}, \mathrm{AE}, \mathrm{CD}, \mathrm{DE}$ are significant model terms. The insignificant model terms can be eliminated to improve the model. In this study, backward elimination procedure was used to reduced the insignificant terms. The predicted $\mathrm{R}^{2}$ of 0.9775 is in reasonable agreement with the adjusted $R^{2}$ of 0.9832 . The adjusted $R^{2}$ value corrects the $R^{2}$ value for the sample size and for number of terms used in the model. The high adjusted $\mathrm{R}^{2}$ value (0.9832) obtained from ANOVA analysis indicating that the developed model is highly significant (Akhnazarova and Kafarov, 1982; Box et al., 1978). "Adeq Precision" measures the signal to noise ratio. A ratio greater than 4 is desirable. From this study, the obtained ratio of 65.547 indicates an adequate signal. This model can be used to navigate the design space.

The model shows standard deviation (SD), mean, and predicted residual sum of squares (PRESS) value of 19.07, 3232.09 and 35513.75. Here, the calculated value of coef- ficient of variation (C.V \%) is 0.59 and this lower value of C.V \% designates a better reliability of the model (Khuri and Cornell, 1987). A corelation coefficient $\left(\mathrm{R}^{2}\right)$ of 0.9861 was obtained indicating high degree of corelation between the experimental parameters and response (SA of PPO in Unit/mg of protein).

The experimental results of the CCD design were fitted with a second order polynomial equation. The Eq. 3 depicts the empirical relationship between specific activity of extracted PPO (SA) and the six independent variables in coded units obtained by applying RSM.

$\mathrm{SA}=3232.09-140.55 \times \mathrm{A}-21.58 \times \mathrm{B}+24.67 \times \mathrm{C}+$ $40.61 \times \mathrm{D}+27.95 \times \mathrm{E}-16.52 \times \mathrm{F}+5.92 \times \mathrm{A} \times \mathrm{B}-9.20 \times$ $\mathrm{A} \times \mathrm{C}-17.08 \times \mathrm{A} \times \mathrm{D}-11.42 \times \mathrm{A} \times \mathrm{E}+10.95 \times \mathrm{C} \times \mathrm{D}+$ $9.48 \times \mathrm{D} \times \mathrm{E}-4.70 \times \mathrm{E} \times \mathrm{F}$

While, the final empirical relationship between response:SA and the six independent process variables in actual units obtained by the applyication of RSM is given by Eq.4:

SA $\left(\mathrm{U}\right.$ mg of protein $\left.{ }^{-1}\right)=3395.26878-0.55455 \times$ $\mathrm{BC}-15.23047 \times \mathrm{PB}+4.56171 \times \mathrm{ET}+2.16974 \times \mathrm{ETM}$ $+20.2743 \times \mathrm{PC}-0.023652 \times \mathrm{VB}+0.014805 \times \mathrm{BC} \times$ PB- $0.00836648 \times \mathrm{BC} \times \mathrm{ET}-0.00474392 \times \mathrm{BC} \times \mathrm{ETM}-$ $0.028555 \times \mathrm{BC} \times \mathrm{PC}+0.11064 \times \mathrm{ET} \times \mathrm{ETM}+0.26345$ $\times \mathrm{ETM} \times \mathrm{PC}-0.00587891 \times \mathrm{PC} \times \mathrm{VB}$

The normal probability described in Fig. 1. which shows some scatters along the line which indicates that the residuals follow a normal distribution. This designates that the model satisfies the assumptions of the ANOVA

Tab. 3. ANOVA table for response surface quadratic model (Response: SA of PPO)

\begin{tabular}{|c|c|c|c|c|c|c|}
\hline Source & Sum of Squares & df & Mean Square & F Value & \multicolumn{2}{|c|}{$\begin{array}{c}\text { p-value } \\
\text { Prob > F }\end{array}$} \\
\hline Model & 1555515.953 & 13 & 119655.0733 & 328.9579291 & $<0.0001$ & Significant \\
\hline$A-B C$ & 1264219.141 & 1 & 1264219.141 & 3475.614522 & $<0.0001$ & \\
\hline B-PB & 29799.39063 & 1 & 29799.39063 & 81.92503299 & $<0.0001$ & \\
\hline C-ET & 38956.89063 & 1 & 38956.89063 & 107.1010005 & $<0.0001$ & \\
\hline D-ETM & 105543.7656 & 1 & 105543.7656 & 290.1628624 & $<0.0001$ & \\
\hline E-PC & 50008.14062 & 1 & 50008.14062 & 137.4833003 & $<0.0001$ & \\
\hline F-VB & 17457.01563 & 1 & 17457.01563 & 47.99314855 & $<0.0001$ & \\
\hline $\mathrm{AB}$ & 2244.390625 & 1 & 2244.390625 & 6.170320001 & 0.0158 & \\
\hline $\mathrm{AC}$ & 5420.640625 & 1 & 5420.640625 & 14.90252494 & 0.0003 & \\
\hline $\mathrm{AD}$ & 18666.39063 & 1 & 18666.39063 & 51.31798455 & $<0.0001$ & \\
\hline $\mathrm{AE}$ & 8349.390625 & 1 & 8349.390625 & 22.95429833 & $<0.0001$ & \\
\hline $\mathrm{CD}$ & 7678.140625 & 1 & 7678.140625 & 21.10888548 & $<0.0001$ & \\
\hline $\mathrm{DE}$ & 5757.015625 & 1 & 5757.015625 & 15.82729328 & 0.0002 & \\
\hline EF & 1415.640625 & 1 & 1415.640625 & 3.891905253 & 0.0531 & \\
\hline Residual & 21824.38471 & 60 & 363.7397452 & & & \\
\hline Lack of Fit & 21824.38471 & 51 & 427.929112 & & & \\
\hline Pure Error & 0 & 9 & 0 & & & \\
\hline Cor Total & 1577340.338 & 73 & & & & \\
\hline Std. Dev. & 19.07196228 & & R-Squared & 0.986163807 & & \\
\hline Mean & 3232.094595 & & Adj R-Squared & 0.983165966 & & \\
\hline C.V. \% & 0.590080572 & & Pred R-Squared & 0.97748504 & & \\
\hline PRESS & 35513.75454 & & Adeq Precision & 65.54743972 & & \\
\hline
\end{tabular}


which depicting the accuracy and applicability of RSM in optimizing all six parameters to maximize the extraction of PPO.

\section{Effect of experimental parameters on PPO extraction}

The perturbation plot describes the comparative effect of all the parameters at the midpoint (coded 0.00) in the design space shown in Fig. 2. The most influential factor is characterized by a steep slope or curvature in a perturbation plot which shows that the response is very sensitive to that factor. In this study, perturbation plot suggests that all variables exerted different degree of quadratic effects. But the curve with the most significant change was the perturbation curve of variable $\mathrm{A}$ i.e. $\mathrm{BC}$ compared to those of the other factors fixed at their maximum levels. Thus, it is obvious that $\mathrm{BC}$ i.e. concentration of phosphate buffer was the most significant factor that contributed to the extraction of PPO and had the most pronounced quadratic effect.

The 3D response surface plots obtained from RSM study shows the interaction or combined effect of the variables on SA. As presented in Fig. 3(A), sharp increase in SA was observed with the decrease of both $\mathrm{BC}$ and $\mathrm{PB}$ when other parameters were kept as constant. Similarly, the value of SA gradually increases with the increase of PC and decrease of VB (Fig. 3B). Therefore lowering of volume and concentration of extraction buffer (Phosphate buffer) facilitates the extraction of $\mathrm{PPO}$ as value of SA increases. The reason may be that lowering of buffer concentration may facilitate the interaction between potato peel and extraction media whereas lowering volume of extraction buffer concentrates the enzyme. PMSF is serine protease
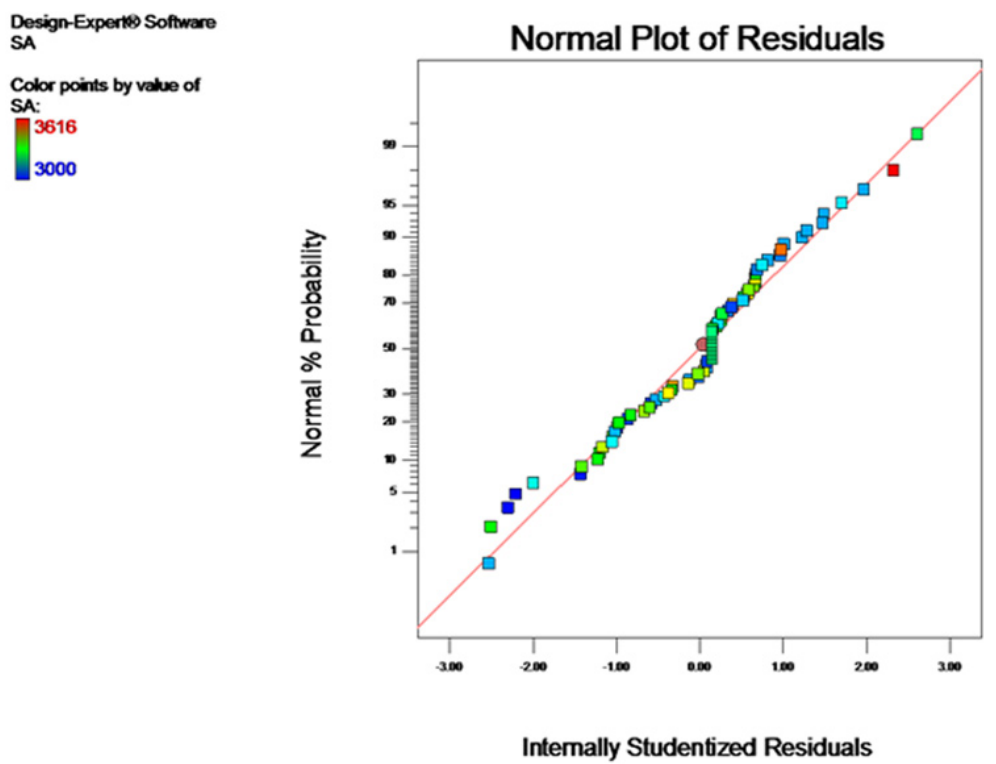

Fig.1. Normal plot of residuals for SA (Unit/ mg of protein)
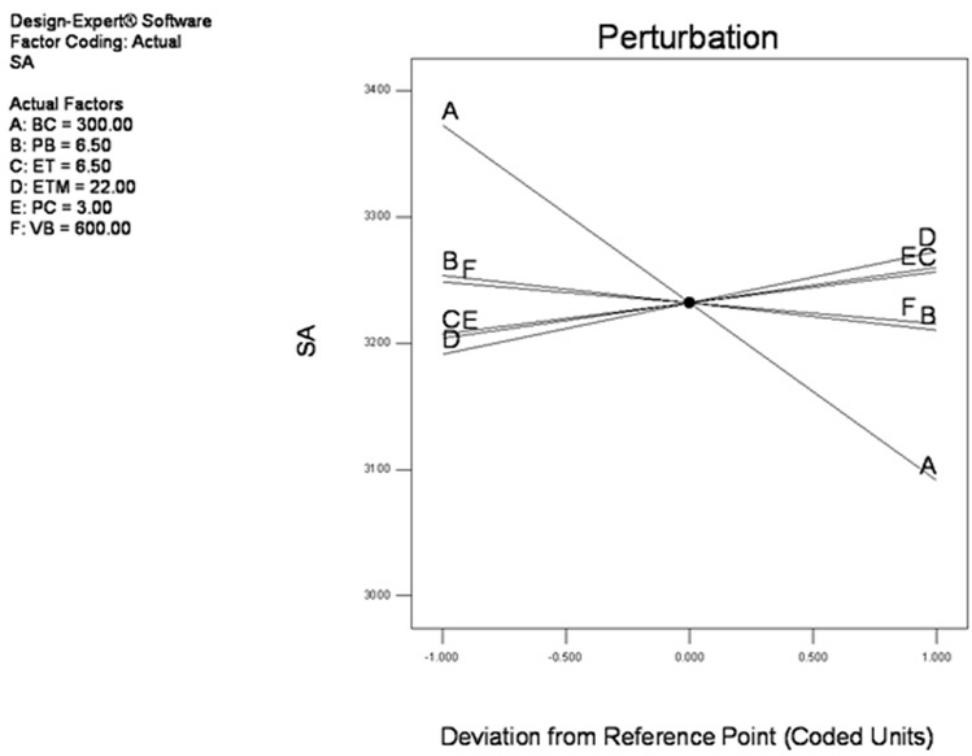

Fig. 2. Perturbation plot of independent process variables 


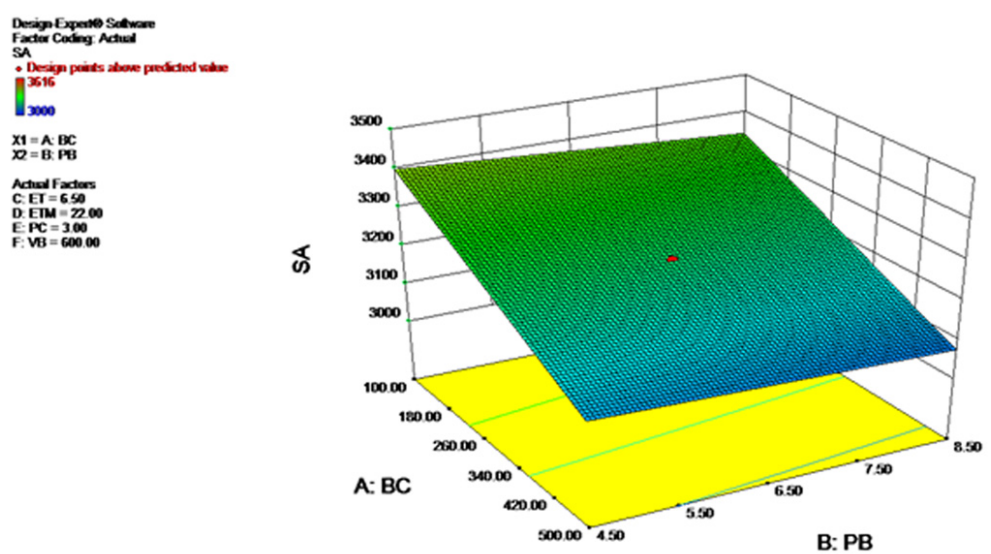

Fig. 3A. Three dimensional plots for the interaction effect of volume of extraction buffer (VB) and PMSF concentration (PC) on SA

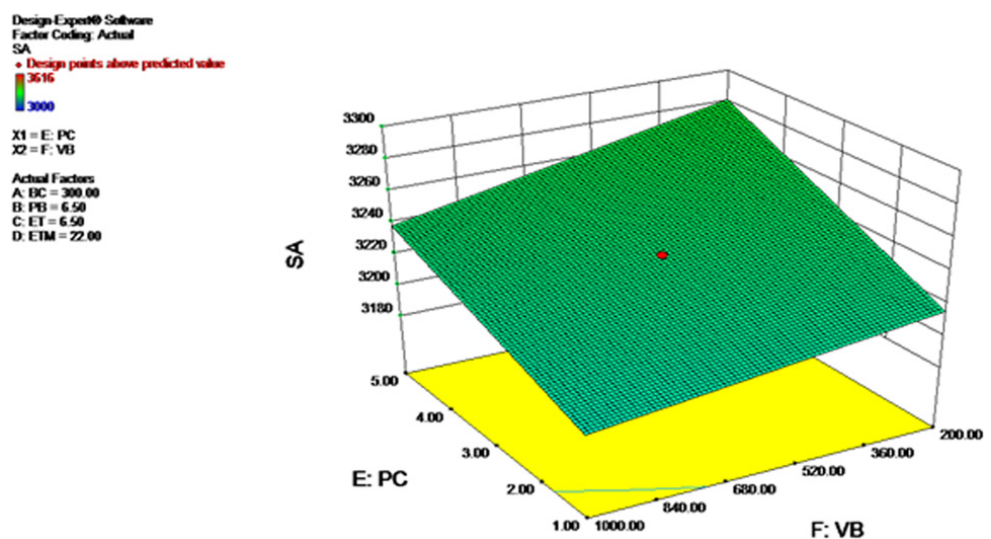

Fig. 3B. Three dimensional plots for the interaction effect of extraction time (ET) and temperature (ETM) on SA

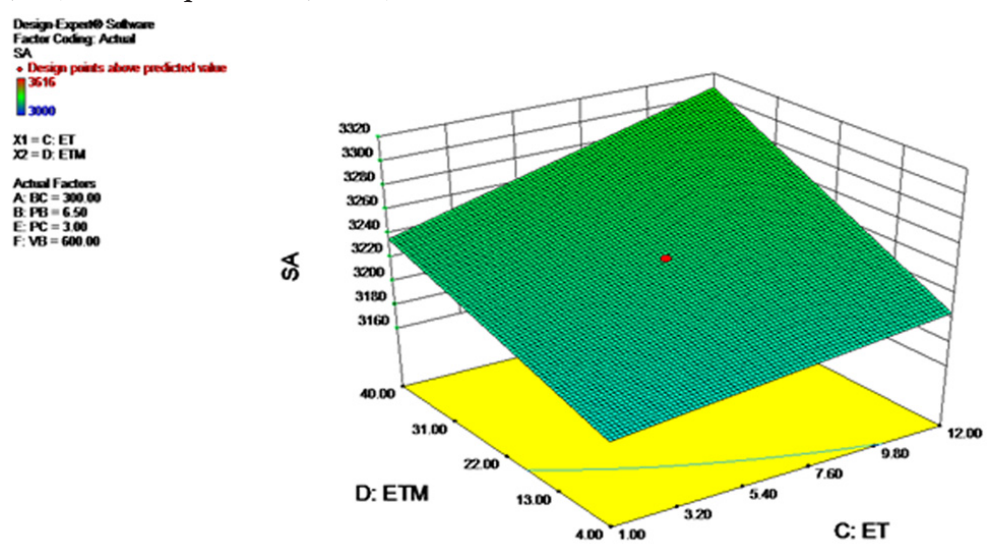

Fig. 3C. Three dimensional plots for the interaction effect of concentration of extraction buffer $(\mathrm{BC})$ and $\mathrm{p}^{\mathrm{H}}$ of extraction buffer $(\mathrm{PB})$ on $\mathrm{SA}$

inhibitor and increase concentration of this compound in the extraction buffer positively influence $S A$ as it prevents the proteolysis of PPO by irreversibly blocking the serine residue of protease present in its active site (Gauillard and Richard-Forguet, 1997; Staszczak et al., 2000).

Significant increase in SA is observed with the increase of both ET and ETM (Fig. 3(C)). From Fig. 3(A), it is evident that extraction of PPO is positively influenced by acidic $\mathrm{pH}$ as $\mathrm{SA}$ increases with the decrease with $\mathrm{pH}$. It may be due to the fact that acidic $\mathrm{p}^{\mathrm{H}}$ may induce confor- mational change in the $3 \mathrm{D}$ structure of $\mathrm{PPO}$ which may results to expose the active site of PPO. Though this fact needs experimental proof, researchers have reported the allosteric behavior of PPO (Ricquebourg et al., 1996) and it has also been reported that PPO activity increases with increase in acidity (Valero et al., 1992).

Extraction of PPO is greatly influenced by time and temperature (Fig. 3(C)) because increase of extraction time prolongs the interaction between potato peels homogenate and extraction media. But, longer extraction 
Tab. 4. Validation of the final reduced quadratic model

\begin{tabular}{|c|c|c|c|c|c|c|}
\hline Parameters & Run 1 & Run 2 & Run 3 & Run 4 & Run 5 & Run 6 \\
\hline Buffer Concentration (BC) & 50 & 200 & 400 & 450 & 550 & 600 \\
\hline $\mathrm{pH}$ of Buffer $(\mathrm{PB})$ & 4 & 5 & 5.5 & 7 & 9 & 9.5 \\
\hline Extraction time $(\mathrm{ET})$ & 0.5 & 2 & 4 & 6 & 8 & 13 \\
\hline Extraction temperature (ETM) & 2 & 6 & 12 & 24 & 36 & 42 \\
\hline PMSF Concentration (PC) & 0.5 & 1.5 & 2 & 4 & 5.5 & 6 \\
\hline Volume of Buffer (VB) & 50 & 100 & 250 & 500 & 700 & 1100 \\
\hline Predicted error $(\%)^{a)}$ & 0.07 & 0.09 & 0.146 & 0.304 & 0.90 & 0.058 \\
\hline \multicolumn{7}{|c|}{ Specific activity $(\mathrm{SA})$ in Units/mg of protein } \\
\hline Predicted & 3323.5 & 3254.09 & 3139.19 & 3090.4 & 2978.26 & 2919 \\
\hline Actual & 3320 & 3260 & 3130 & 3080 & 2970 & 2940 \\
\hline Predicted error $(\%)^{\mathrm{a})}$ & 0.10 & 0.18 & 0.29 & 0.33 & 0.26 & 0.72 \\
\hline
\end{tabular}

Predicted error $=($ actual value-predicted value $) \times 100 /$ predicted value
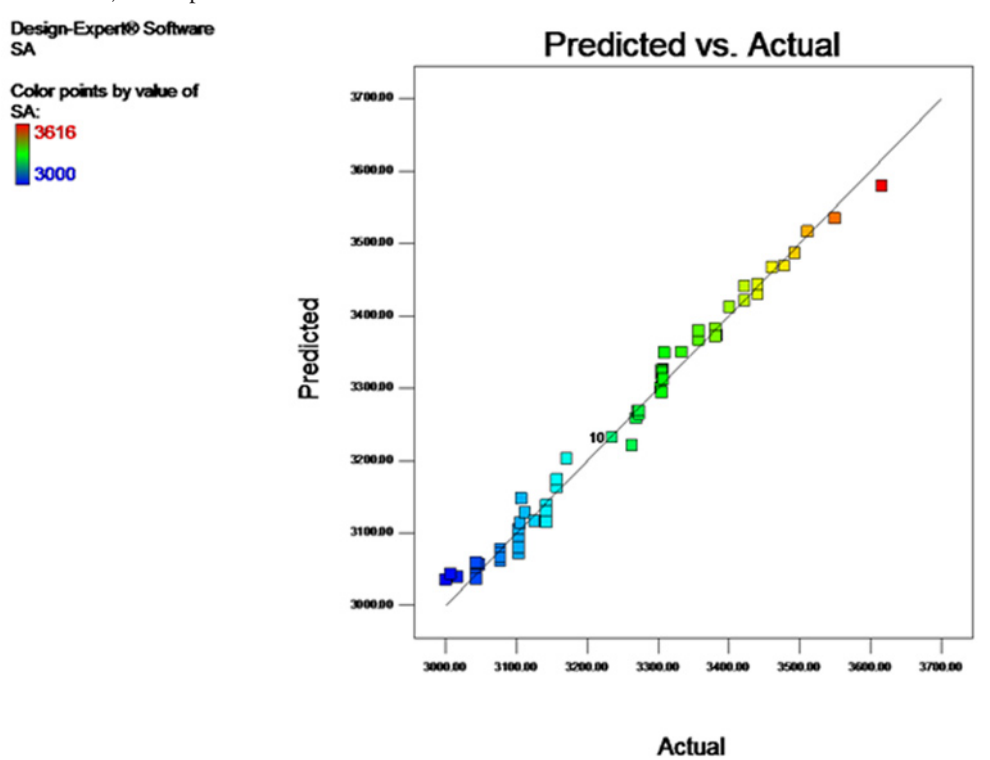

Fig. 4. Plot of predicted versus actual values of response (SA in Units/mg of protein)

period increases process economics and also chances of proteolysis. Rise in temperature increases SA of PPO by increasing the activity of PPO. So, the magnitude of all these parameters should be optimized to maximize the extraction of PPO.

\section{Validation of developed model}

Plot of experimental or actual value $v s$. predicted values of SA (given in Fig. 4) represents a high degree of similar-

Tab.5. Constraints for optimization of extraction conditions

\begin{tabular}{cccc}
\hline \multicolumn{4}{c}{ Constraints } \\
\hline Name & Goal & Lower Limit & UpperLimit \\
\hline A:BC & Minimize & 100 & 500 \\
B:PB & Is in range & 4.5 & 8.5 \\
C:ET & Minimize & 1 & 12 \\
D:ETM & Is in range & 4 & 40 \\
E:PC & Is in range & 1 & 5 \\
F:VB & Minimize & 200 & 1000 \\
SA & Maximize & 3000 & 3616 \\
\hline
\end{tabular}

ity which designates the accuracy of the developed method. It also describes that the developed model satisfy the variance requirement and these also reflect applicability and accuracy of RSM for improved extraction of PPO.

The developed model was further validated by performing six additional experiments which constitutes three experimental combinations from the design and remaining three experiments were those which have not been used previously. As summarized in Tab. 4, experimental values were reasonably close to the predicted values confirming the validity and adequacy of the proposed model. Moreover, the validation experiments also proved that the predicted values of SA could be satisfactorily achieved within $0.80 \%$ of predicted error of experimental values.

\section{Optimization of extraction condition}

In the present study, desirability function optimization of the RSM has been employed for the optimization of the extraction of PPO by means of the response; SA. The optimization module searches a combination of factor levels that simultaneously satisfies the requirements placed on 
106

Tab. 6. Optimization result

\begin{tabular}{ccccccccc}
\hline Solutions No. & BC & PB & ET & ETM & PC & VB & SA & Desirability \\
\hline 1 & 100.00 & 4.50 & 1.00 & 40.00 & 5.00 & 200.00 & 3483.08 & $0.94104-$ Selected \\
2 & 100.00 & 4.57 & 1.01 & 40.00 & 5.00 & 200.57 & 3482.12 & 0.94017 \\
3 & 100.03 & 4.50 & 1.15 & 40.00 & 4.98 & 211.58 & 3483.16 & 0.93443 \\
4 & 100.02 & 4.50 & 1.00 & 40.00 & 4.71 & 211.60 & 3474.64 & 0.93348 \\
5 & 101.55 & 4.50 & 1.00 & 37.48 & 5.00 & 209.51 & 3473.45 & 0.93262 \\
6 & 100.11 & 4.50 & 1.09 & 39.71 & 4.27 & 200.11 & 3463.41 & 0.92928 \\
7 & 100.01 & 6.13 & 1.00 & 40.00 & 4.66 & 200.12 & 3451.55 & 0.92525 \\
\hline 8 & 100.06 & 6.86 & 1.03 & 39.70 & 5.00 & 200.03 & 3449.89 & 0.92372 \\
9 & 101.87 & 4.50 & 1.13 & 30.00 & 4.99 & 200.43 & 3451.04 & 0.92115 \\
10 & 101.02 & 4.50 & 1.02 & 32.66 & 3.77 & 200.11 & 3428.98 & 0.91238 \\
11 & 100.00 & 4.96 & 2.41 & 40.00 & 5.00 & 200.00 & 3488.23 & 0.9118 \\
12 & 100.00 & 7.98 & 1.00 & 39.18 & 4.73 & 201.25 & 3425.48 & 0.91129 \\
13 & 100.00 & 7.86 & 1.00 & 38.82 & 4.67 & 200.00 & 3424.55 & 0.91114 \\
14 & 100.00 & 4.67 & 1.00 & 32.53 & 3.49 & 200.00 & 3419.91 & 0.90865 \\
\hline 15 & 100.03 & 4.50 & 1.00 & 28.83 & 3.75 & 200.02 & 3418.35 & 0.90775 \\
\hline
\end{tabular}

each of the responses and factors in an attempt to establish the appropriate model. The aim of this optimization process was to find the optimum values of extraction parameters in order to maximize the value of SA in the extract. The constraints used during optimization process are summarized in Tab. 5. As one of the major aims of this study was to reduce process economics, the minimum level of two parameters viz. concentration and volume of extraction media (phosphate buffer) were used. Minimum value of extraction time was also taken to make the method less time consuming. The optimum experimental conditions required for maximum extraction of $\mathrm{PPO}$ from of potato peels are phosphate buffer concentration of $100 \mathrm{~mm}$, buffer $\mathrm{pH}$ of 4.5 , extraction time of 1 hour, $40^{\circ} \mathrm{C}$ temperature, PMSF concentration of $5 \mathrm{mM}$ and buffer volume of 200 $\mathrm{ml}$. The desirability of this optimization model is $94.10 \%$ (Tab. 6.) which is very much acceptable.

\section{Conclusions}

The CCD employed in this study proved to be an effective tool for the optimization of six influential process parameters to maximize the extraction of PPO. The best models were achieved by modified response surface model using backward elimination and these models provide good quality predictions for the six independent variables in terms of the extraction of PPO. The results of the present studies revealed that several factors influence the extraction of PPO and its activity. From the response surface analysis, $\mathrm{BC}$ had the most significant effect on SA among the six parameters studied. The results of ANOVA analysis which demonstrated optimal experimental conditions for extraction of PPO with maximum SA (3572.74 Units/mg of protein) were $\mathrm{BC}$ of $100 \mathrm{~mm}$, $\mathrm{PB}$ of 4.5, ET of 1 hour, ETM of $40^{\circ} \mathrm{C}$, PC of $5 \mathrm{mM}$ and VB of $200 \mathrm{ml}$. This extraction model is cost effective and time saving as it requires low instrumental support. Further experiments including purification, characterization and immobilization of $\mathrm{PPO}$ from potato peel are currently under way.

\section{Acknowledgements}

The authors are grateful to Council of Scientific and Industrial Research (CSIR), Govt. of India for providing financial grant. The help and rendered by the scientific and technical staffs of Centre for Advanced Materials Processing, CSIR-CMERI, Durgapur is acknowledged.

\section{References}

Akhnazarova S, Kafarov V (1982). Experiment optimization in chemistry and chemical engineering. Mir Publishers, Moscow and Chicago $312 \mathrm{p}$.

Amjad AK, Suhail A, Qayyum H (2009). Direct immobilization of polyphenol oxidases on Celite 545 from ammonium sulphate fractioned proteins of potato (Solanum tuberosum). J Mol Catal B-Enzym 40:58-63.

Aydemir T (2010). Selected kinetic properties of polyphenol Oxidase extracted from Rosmarinus officinalis L. Int J Food Prop 13:475-485.

Bas D, Boyaci IH (2007). Modeling and optimization I: Usability of response surface methodology. J Food Eng 78:836-845.

Box GEP, Hunter WG, Hunter JS (1978). Empirical Model Building and Response Surfaces, 291-334 p. In: Statistics for Experiments, Wiley, New York.

Chen CS, Liu KJ, Lou YH, Shieh CJ (2002). Optimization of kojic acid monolaurate synthesis PS from Pseudomonas cepacia. J Sci Food Agric 82:601-605.

Do-Yoon K, Woo-Yean K (1996). Purification of glycosylated polyphenol oxidase from potato. J Biochem Mol Biol 29:163-168.

Duran N, Rosa MA, D’Annibale A, Gianfreda L (2002). Applications of laccases and tyrosinases (phenoloxidases) immobilized on different supports: a review. Enzyme Microb 
Tech 31:907-931.

Ebrahimpour A, Rahman RNZRA, Ean Ch'ng DH, Basri M, Salleh AB (2008). A modeling study by response surface methodology and artificial neural network on culture parameters optimization for thermostable lipase production from a newly isolated thermophilic Geobacillus sp. strain ARM. BMC Biotechnol 8:96.

Gauillard F, Richard-Forguet F (1997). Polyphenoloxidases from 'Williams' pear (Pyrus communis L., cv 'Williams'): activation, purification and some properties. J Sci Food Agric 74:49-56.

Gaur R, Gupta A, Khare SK (2008). Lipase from solvent tolerant Pseudomonas aeruginosa strain: Production optimization by response surface methodology and application. Bioresour Technol 99:4796-4802.

Gomez-Lopez VM (2002). Some biochemical properties of polyphenol oxidase from two varieties of avocado. Food Chem 77:163-169.

Hameed BH, Tan IAW, Ahmad AL (2009). Preparation of oil palm empty fruit bunch-based activated carbon for removal of 2,4,6-trichlorophenol: Optimization using response surface methodology. J Hazardous Mater 164:1316-1324.

Khuri AI, Cornell JA (1987). Response Surfaces: Design and Analysis. Marcel Dekker, New York.

Klibanov AM, Alberti BN, Morris ED, Felshin LM (1980). Enzymatic removal of toxic phenols and anilines from waste waters. Appl Biochem 2:414-421.

Langdon TT (1987). Preventing browning in freshly prepared potatoes without the use of sulfating agents. Food Tech 41:64-67.

Lee MY, Lee MK, Park I (2007). Inhibitory effect of onion extract on polyphenol oxidase and enzymatic browning of taro (Colocasia antiquorum var. esculenta). Food Chem 105:528-532.

López-Molina D, Hiner ANP, Tudela J, Garcì-Cánovas F, López JNR (2003). Enzymatic removal of phenols from aqueous solution by artichoke (Cynara scolymus L.) extracts. Enzyme Microb Tech 33:738-742.

Lowry HO, Rosebrough NJ, Farr AL, Randall RJ (1951). Protein measurement with the Folin phenol reagent. J Biol Chem 193:265-275.

Manohar B, Divakar S (2004). Applications of surface plots and statistical design to selected lipase-catalyzed esterification reactions. Process Biochem 39:847-853.

Marri C, Frazzoli A, Hochkoeppler A, Poggi V (2003). Purification of a polyphenol oxidase isoform from potato (Solanum tuberosum) tubers. Phytochem 63:745-752.

Mohammadi A, Moghaddam AB, Dinarvand R, Rezaei-Zarchi $S$ (2009). Direct electron transfer of polyphenol oxidase on carbon nanotube surfaces: application in biosensing. Int J Electrochem Sci 4:895-905.

Ni Eidhin D, Degn P, O'beirne D (2010). Characterization of polyphenol oxidase from rooster potato (Solanum tuberosum cv 'Rooster'). J Food Biochem 34:13-30.

Niladevi KN, Prema P (2008). Immobilization of laccase from Streptomyces psammoticus and its application in phenol removal using packed bed reactor. World J Microb Biot 24:1215-1222.

Oktay M, Küfreviolu I, Kocaçaliskan I, Sakirolu H (1995). Polyphenoloxidase from 'Amasya' apple. J Food Sci 60:494 496.

Palma-Orozco G, Ortiz-Moreno A, Dorantes-Álvarez L, Sampedro JG, Nájera H (2011). Purification and partial biochemical characterization of polyphenol oxidase from mamey (Pouteria sapota). Phytochemistry 72:82-88.

Ranjan D, Srivastava P, Talat M, Hasan SH (2009). Biosorption of Arsenic from aqueous solution using agricultural residue "Rice Polish". J Hazard Mater 166:1050-1059.

Ricquebourg SL, Da Silva CR, Rouch CC, Cadet FR (1996). Theoretical support for a conformational change of polyphenol oxidase induced by metabisulfite. J Agric Food Chem 44:3457-3460.

Sener A, Ümit Ünal M (2011). Purification and characterization of polyphenol oxidase from Akko XIII Loquat (Eriobotrya japonica cv 'Akko XIII'). Food Biotechnol 25:30-42.

Seo SY, Sharma VK, Sharma N (2003). Mushroom tyrosinase: recent prospects. J Agric Food Chem 51:2837-2853.

Shan D, Zhu M, Han E, Xue H, Cosnier S (2007). Calcium carbonate nanoparticles: A host matrix for the construction of highly sensitive amperometric phenol biosensor. Biosens Bioelectron 23:648-654.

Staszczak M, Zdunek E, Leonowicz A (2000). Studies on the role of proteases in the white-rot fungus Trametes versicolor: effect of PMSF and chloroquine on ligninolytic enzymes activity. J Basic Microbiol 40:51-63.

Sztajer H, Maliszewska I, Wieczorek J (1988). Production of exogenous lipases by bacteria, fungi, and actinomycetes. Enzyme Microb Tech 10:492-497.

Thygesen WP, Dry IB, Robinson SP (1995). Polyphenol oxidase in potato' a multigene family that exhibits differential expression patterns. Plant Physiol 109:525-531.

Torres E, Bustos-Jaimes I, Le Borgne S (2003). Potential use of oxidative enzymes for the detoxification of organic pollutants. Appl Catal B: Environ 46:1-15.

Valero E, Garcia-Carmona F (1992). pH-induced kinetic co-operativity of a thylakoid-bound polyphenol oxidase. Biochem J 286:623-626.

Vohra A, Satyanarayana T (2002). Statistical optimization of the medium components by response surface methodology to enhance phytase production, Pichia anomala. Process Biochem 37:999-1004.

Yang C, Fujita S, Kohno K, Kusubayashi A, Ashrafuzzaman MD, Hayashi N (2001). Partial purification and characterization of polyphenol oxidase from banana (Musa sapientum L.) Peel. J Agric Food Chem 49:1446-1449. 